\title{
Hành vi lãnh đạo ảnh hưởng đến sự hài lòng và hiệu suất công việc của nhân viên y tế các bệnh viện công tại Thành phố Hồ Chí Minh \\ Leadership behaviors influence medical staff's satisfaction and performance public hospitals in Ho Chi Minh City
}

\author{
Phan Cảnh Pháp ${ }^{1,2^{*}}$, Huỳnh Chí Dũng ${ }^{2,3}$, Mai Ngọc Khương ${ }^{2}$ \\ ${ }^{1}$ Bệnh viện Thống Nhất, Việt Nam \\ ${ }^{2}$ Đại học Quốc tế - ĐHQG TP. HCM, Việt Nam \\ ${ }^{3}$ Đài tiếng nói Nhân dân Thành phố Hồ Chí Minh, Việt Nam \\ *Tác giả liên hệ, Email: phancanhphap@gmail.com
}

THÔNG TIN

DOI:10.46223/HCMCOUJS. econ.vi.16.1.586.2021

Ngày nhận: 22/07/2020

Ngày nhận lại: 07/08/2020

Duyệt đăng: 16/08/2020

Tù khóa:

chuyển hóa, hài lòng, hiệu suất, trao đồi

Keywords:

transformational, satisfaction, performance, transactional
TÓM TẮT
Nghiên cứu định lượng này với số lượng mẫu là 938 phiếu khảo sát được lấy từ nhân viên y tế của 5 bệnh viện công lập trên địa bàn Thành phố Hồ Chí Minh nhằm tìm ra các nhóm hành vi lãnh đạo có tác động có ý nghĩa đến sự hài lòng và hiệu suất công việc của đội ngũ nhân viên y tế trong các bệnh viện công. Sử dụng phương pháp bình phương nhỏ nhất một phần PLS-SEM kỹ thuật mô hình hóa phương trình cấu trúc bằng phần mềm Smart PLS 3.0, Bootstrapping không tham số với 2.000 lần lặp lại để đánh giá, kiểm định thang đo, kiểm định mô hình cấu trúc và kiểm định các giả thuyết. Kết quả nghiên cứu chỉ ra có 2 yếu tố thuộc hành vi lãnh đạo trao đổi; thưởng theo thành tích và quản lý ngoại lệ chủ động và 1 yếu tố thuộc hành vi lãnh đạo chuyển hóa; ảnh hưởng lý tưởng thuộc tính tác động có ý nghĩa đến sự hài lòng và hiệu suất làm việc của nhân viên y tế tại các bệnh viện công lập. Nghiên cứu cũng xác định có sự tác động tích cực của sự hài lòng đến hiệu suất làm việc.

\section{ABSTRACT}

This quantitative study with a sample size of 938 surveys collected from the medical staff of 5 public hospitals in Ho Chi Minh City aims to identify which leadership behaviors significantly influence medical staff's job satisfaction and performance in public hospitals. The least-squares method of PLSSEM was used with Smart PLS 3.0 software, non-parametric Bootstrapping with 2,000 repetitions for evaluation and validation of scales and test of hypotheses. The results showed that there are 2 factors of transactional leadership; contingent reward and management by exception (active) and 1 factor of transformational leadership; idealized influences (attributes) significantly affect medical staff's satisfaction and performance in public hospitals. The study also identified a positive impact of job satisfaction on performance. 


\section{Giới thiệu}

Hành vi lãnh đạo là một trong những yếu tố có ảnh hưởng đáng kể trong việc quản lý nguồn nhân lực, tác động đến sự hài lòng và hiệu suất làm việc của nhân viên. Đây là hai trong những yếu tố quan trọng, có ý nghĩa quyết định đến sự tồn tại và phát triển của mỗi tổ chức. Vậy, hành vi lãnh đạo nào có tác động tích cực đến sự hài lòng và hiệu suất làm việc của nhân viên? Trên thế giới có khá nhiều nghiên cứu về hành vi lãnh đạo trao đổi và chuyển hóa cho kết quả tác động khác nhau đến sự hài lòng và hiệu suất làm việc của nhân viên như nghiên cứu của Rachmawati (2015), Awamleh và Al-Dmour (2011), Nazim (2016),.. Ở Việt Nam cũng có một vài nghiên cứu về mảng đề tài này của tác giả (Khang, 2013; Tri \& Ut, 2017) nhưng còn rất ít nhất là đối với nhân viên y tế tại các bệnh viện công. Trong khi đó thực trạng nhân viên y tế không hài lòng với môi trường làm việc ở các bệnh viện công dẫn đến việc chuyển dịch ra các bệnh viện tư đang là vấn đề đáng quan tâm hiện nay. Tình trạng nhân viên y tế làm việc hiệu suất thấp làm cho bệnh nhân phàn nàn, kém hài lòng ở các bệnh viện công cũng nhiều hơn các bệnh viện tư. Thực trạng đó do nhiều nguyên nhân, một trong những nguyên nhân là do cách điều hành của người lãnh đạo, quản lý. Mục đích của nghiên cứu này để tìm hiểu các yếu tố nào thuộc hành vi lãnh đạo trao đổi và chuyển hóa có tác động đến sự hài lòng và hiệu suất làm việc của nhân viên, mức độ tác động là bao nhiêu, tác động tích cực hay tiêu cực. Đồng thời nghiên cứu cũng đánh giá sự tác động của sự hài lòng đối với hiệu suất làm việc của nhân viên. Trên cơ sở đó đề xuất các giải pháp giúp cho người lãnh đạo ở các bệnh viện công xây dựng hành vi lãnh đạo phù hợp nhằm nâng cao sự hài lòng và hiệu suất làm việc cho nhân viên.

\section{Cơ sở lý thuyết}

\subsection{Lãnh đạo trao đổi (Transactional leadership)}

Người tiên phong trong việc đưa ra các khái niệm về hành vi lãnh đạo và chuyển hóa là Burns (1978), trên cơ sở đó Bass (1985) đã đề xuất một lý thuyết mới về sự lãnh đạo và chỉ ra các thành phần của nó. Lãnh đạo trao đổi dựa trên quá trình trao đổi nơi người lãnh đạo điều hành phần thưởng và chế tài. Bằng cách này hay cách khác, người lãnh đạo và người theo họ đồng ý hoặc ngầm định rằng hành vi mong muốn sẽ được khen thưởng, trái lại sẽ bị hình phạt. Có thể thấy rằng kiểu lãnh đạo này không thỏa đáng cho hầu hết các tình huống (Awamleh \& Al-Dmour, 2011).

Theo Nazim (2016), mục tiêu chính của lãnh đạo trao đổi là yêu cầu nhân viên làm việc tốt để được phần thưởng. Nếu công việc không được thực hiện đúng có thể có hậu quả tiêu cực. Một nhà lãnh đạo trao đổi đặt ra các mục tiêu và làm rõ mối quan hệ giữa hiệu suất và phần thưởng cho nhân viên. Nhân viên biết những gì họ được yêu cầu phải làm để nhận phần thưởng. Nếu hiệu suất của cấp dưới không theo tiêu chuẩn được xác định trước thì hình phạt cũng được đưa ra cho cấp dưới. Cấp dưới được hướng dẫn rõ ràng để có được kết quả mong muốn. Khi người lãnh đạo giao nhiệm vụ cho cấp dưới, họ được coi là phải chịu trách nhiệm. Quản lý bằng ngoại lệ thường được sử dụng bởi các nhà lãnh đạo trao đổi. Nếu hiệu suất tốt thì khen ngợi và phần thưởng được trao cho nó. Hành động khắc phục cũng có nếu hiệu suất dưới mức mong đợi. Theo Rachmawati (2015) đặc điểm lãnh đạo trao đổi thể hiện qua hành vi của cấp trên như sau: Phần thưởng dự phòng, Quản lý theo ngoại lệ chủ động, quản lý theo ngoại lệ thụ động, phong cách lãnh đạo tự do.

\subsection{Lãnh đạo chuyển hóa (Transformation leadership)}

Theo Awamleh và Al-Dmour (2011) lãnh đạo chuyển hóa quan tâm nhiều hơn đến việc phát triển những người theo dõi đến tiềm năng tối đa của họ (Bass \& Avolio, 1990). Theo mô hình của Bass, lãnh đạo chuyển hóa bao gồm bốn thành phần trung tâm: ảnh hưởng lý tưởng, truyền cảm hứng, quan tâm cá nhân, kích thích trí tuệ. Ảnh hưởng lý tưởng bao gồm cả thuộc tính và 
hành vi của người lãnh đạo là thành phần chính, nó tạo nên sự lôi cuốn, kết nối cảm xúc sâu sắc giữa người lãnh đạo và người theo họ, tạo ra sự phấn khích về công việc (Bass, 1985). Sự lôi cuốn được hình thành thông qua tầm nhìn của người lãnh đạo, nó tạo nên sự tôn trọng và tin tưởng của nhân viên, dẫn đến việc chấp nhận các mục tiêu đầy thách thức (Bass \& Avolio, 1990). Truyền cảm hứng là một khía cạnh quan trọng của mối quan hệ lôi cuốn nhân viên, người lãnh đạo truyền đạt tầm nhìn của họ với sự lạc quan và nhiệt tình. Họ cũng sử dụng các biểu tượng để nâng cao nhận thức về các mục tiêu mong muốn (Bass \& Avolio, 1990). Sự quan tâm cá nhân là nhà lãnh đạo dành sự quan tâm đến từng người nhân viên của mình bằng cách đối xử với họ khác nhau nhưng công bằng (Bass \& Avolio, 1990). Điều đó, đòi hỏi người lãnh đạo nắm chắc nhu cầu và khả năng của từng nhân viên để khuyến khích, hướng dẫn họ trong thực hiện nhiệm vụ. Kích thích trí tuệ chính là khích lệ những người theo dõi để họ tự suy nghĩ và phân tích các vấn đề từ quan điểm cá nhân của họ. Khi tập trung vào kích thích trí tuệ, các nhà lãnh đạo chuyển hóa khuyến khích sự sáng tạo, đổi mới. Những nhà lãnh đạo này nhấn mạnh việc sử dụng cả logic và trực giác để giải quyết vấn đề (Bass \& Avolio, 1990). Để đo lường một cách có hệ thống và đáng tin cậy các thành phần của lãnh đạo chuyển đổi và giao dịch, Bass (1985) đã phát triển Bảng câu hỏi lãnh đạo đa nhân tố (MLQ). Kể từ khi phát triển, MLQ có đã nhận được bằng chứng sâu rộng về độ tin cậy và giá trị của nó, và thường được sử dụng trong nghiên cứu lãnh đạo (Bryman, 1992).

\subsection{Khái niệm về sụ hài lòng}

Theo Lan, Chang, Ma, Zhang, và Chuang (2019) sự hài lòng trong công việc được xem là mức độ mà nhân viên đạt được kết quả tích cực liên quan đến làm việc thông qua một thái độ tích cực và định hướng hiệu quả. Gruneberg (1979) xác định sự hài lòng của công việc là phản ứng tâm lý và thái độ của một cá nhân đối với công việc cụ thể. Spector (1997) coi bản chất sự hài lòng trong công việc là cảm giác tích cực hay tiêu cực đối với công việc. Đó cũng có thể được coi là cấp độ thích thú với công việc của một cá nhân. Một định nghĩa gần đây hơn về khái niệm sự hài lòng trong công việc coi đó là cách một người cảm nhận công việc và mức độ một người thích một công việc (Hulin \& Judge, 2003). Ahmad, Ahmad, và Shah (2010) đã xem xét rằng nhân viên với sự hài lòng công việc cao hơn sẽ cảm thấy một thái độ tích cực hơn đối với công việc của họ. Maurya và Kaushik (2013) coi sự hài lòng của công việc là nội dung hành vi của một nhân viên tại nơi làm việc. Trong nhiều loại nghiên cứu, sự hài lòng trong công việc được coi là ảnh hưởng mạnh mẽ và tích cực đến một tổ chức và giúp nhân viên cải thiện khả năng sáng tạo, kỹ năng giải quyết vấn đề và ra quyết định (Colquitt, Lepine, Wesson, \& Gellatly, 2011). Trên cơ sở lý thuyết từ các học giả và các nghiên cứu trên, chúng tôi sử dụng thang đo Likert năm bậc và 10 yếu tố sau để đo lường sự hài lòng: hài lòng về khối lượng và sự phân công công việc, hài lòng về sự giám sát tại bệnh viện, hài lòng với cơ hội thăng tiến và phát triển nghề nghiệp, hài lòng với sự lựa chọn nghề nghiệp của mình, hài lòng về mối quan hệ giữa nhân viên và cấp quản lý, hài lòng về sự quản lý của bệnh viện, hài lòng với thu nhập và lợi ích mà bệnh viện mang lại, hài lòng với môi trường và điều kiện làm việc, hài lòng về mối quan hệ với đồng nghiệp, hài lòng với công việc hiện tại.

\subsection{Khái niệm về hiệu suất công việc}

Theo Hoxha và Heimerer (2019) hiệu suất công việc được định nghĩa là giá trị mong đợi mà một cá nhân thực hiện được trong một khoảng thời gian tiêu chuẩn và để đạt được giá trị trong khoảng thời gian tiêu chuẩn đó cá nhân phải thực hiện rất nhiều hành vi rời rạc khác nhau, Sonnentag và Frese (2005) cho rằng hiệu suất là một khái niệm đa chiều. Tuy nhiên, các nhà nghiên cứu ở Việt Nam thường đưa ra so sánh giữa hiệu quả và hiệu suất để dễ hiểu hơn, đó là hiệu quả là làm đúng việc còn hiệu suất là làm việc đúng cách. Chúng ta có thể hiểu hiệu suất làm việc là khả năng tránh lãng phí về thời gian, sức lao động, tiền của trong quá trình làm việc mà vẫn đạt được hiệu quả. Có nghĩa là hiệu suất là thực hiện công việc đạt được mục tiêu với nguồn lực bỏ ra 
hợp lý nhất, để thực hiện được việc đó đòi hỏi cá nhân phải làm việc đúng cách, có kế hoạch.

Trên cơ sở các nghiên cứu trước và lý thuyết có liên quan, chúng tôi sử dụng thang đo Likert năm bậc và 11 yếu tố sau để đo lường hiệu suất làm việc: có thể đảm nhận nhiều công việc cùng lúc, đảm bảo dịch vụ luôn đúng tiêu chuẩn đề ra, đồng nghiệp luôn hỏi ý kiến và làm theo hướng dẫn khi họ gặp vấn đề, có khả năng giải thích và trả lời rõ ràng các yêu cầu của người bệnh, phối hợp tốt với các bộ phận khác, bỏ ra nhiều công sức hơn để làm hài lòng người bệnh, cố gắng để trở nên hữu ích với tất cả mọi người, duy trì tốt mối quan hệ với người bệnh ngay cả sau khi họ khỏi bệnh, nắm rõ tất cả những gì liên quan đến dịch vụ của bệnh viện, sẵn sàng phá lệ để làm hài lòng người bệnh, hiệu quả công việc tốt.

\subsection{Mối quan hệ giữa hành vi lãnh đạo trao đổi, lãnh đạo chuyển hóa với hiệu suất làm việc và sụ hài lòng của nhân viên}

Nghiên cứu của Hoxha và Heimerer (2019) cho thấy rằng lãnh đạo chuyển hóa có mối quan hệ tích cực đáng kể với hiệu suất làm việc của nhân viên, hành vi lãnh đạo giao dịch bao gồm phần thưởng dự phòng, quản lý bởi ngoại lệ chủ động và thụ động không dự đoán đáng kể hiệu suất của nhân viên. Lãnh đạo chuyển hóa có tác động tiêu cực đến sự hài lòng của công việc bên trong và bên ngoài, lãnh đạo trao đổi có ảnh hưởng tích cực đến sự hài lòng công việc bên ngoài (Lan et al., 2019).

\section{Phương pháp nghiên cứu}

Nghiên cứu sử dụng phương pháp mô tả cắt ngang, định lượng; sử dụng thang đo được chọn từ các nghiên cứu trước đây với độ tin cậy đã được thiết lập và hiệu lực như nghiên cứu của Faraz, Raza, Yanxia, Ahmed, và Estifo (2018), Khang (2013). Nghiên cứu sử dụng thang đo Likert năm bậc và bảng câu hỏi lãnh đạo đa nhân tố MLQ $(5 X)$ được phát triển bởi Bass và Avolio.

\subsection{Mô hình nghiên cúu}

Trên cơ sở lý thuyết và các nghiên cứu có liên quan, chúng tôi đề xuất mô nghiên cứu:

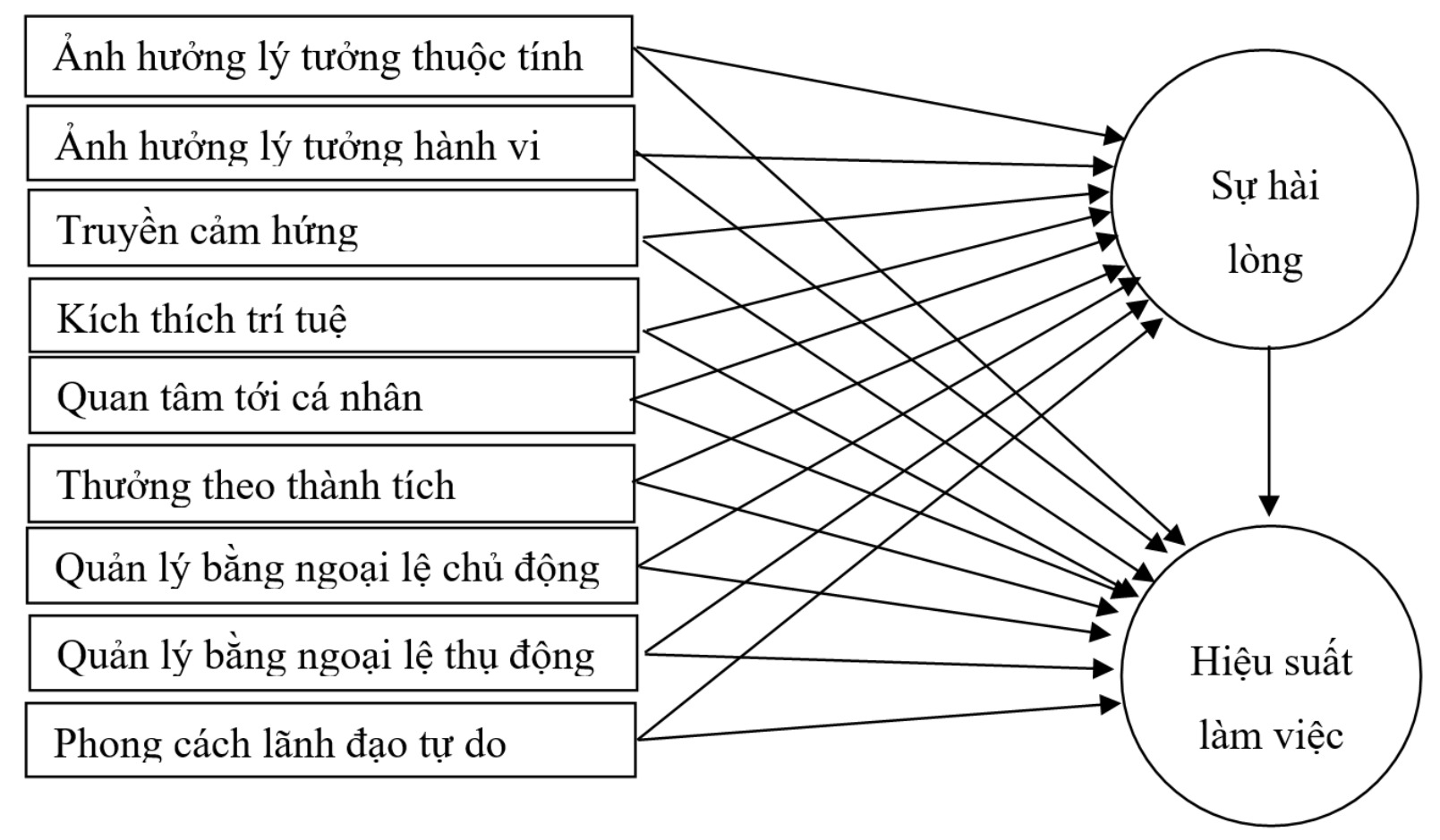

Hình 1. Mô hình nghiên cứu đề xuất 


\subsection{Thu thập dĩu liệu}

Dữ liệu được thu thập bằng cách phát phiếu khảo sát cho nhân viên y tế đang làm việc tại 5 bệnh viện công ở Thành phố Hồ Chí Minh. Đại diện cho tuyến quận huyện (Bệnh viện Thủ Đức), tuyến Thành phố (Bệnh viện Nhân dân 115), tuyến trung ương (Bệnh viện Chợ Rẫy, Thống Nhất, Răng hàm mặt Trung ương Thành phố Hồ Chí Minh); có bệnh viện chuyên khoa (Bệnh viện Răng hàm mặt Trung ương Thành phố Hồ Chí Minh), có bệnh viện đa khoa (4 bệnh viện còn lại). Chọn mẫu theo phương pháp phi xác suất, thuận tiện. Trong nghiên cứu này có 45 biến quan sát, chúng tôi chọn cỡ mẫu với tỷ lệ là 20:1, kích thước mẫu là $900(\mathrm{n}=20 \mathrm{x}$ 45). Chúng tôi thu được 938 phiếu đạt chuẩn để nghiên cứu.

\subsection{Phân tích mô hình đo lường}

Nghiên cứu sử dụng phương pháp bình phương nhỏ nhất PLS-SEM bằng phần mềm Smart PLS 3.0, Bootstrapping không tham số với 2.000 lần lặp lại. Nghiên cứu có hai mô hình: đo lường và cấu trúc. Phân tích mô hình đo lường để xác định tính hợp lệ và độ tin cậy nhất quán nội bộ, tính hợp lệ chứa giá trị hội tụ và giá trị phân biệt. Mô hình cấu trúc và giả thuyết của mô hình được kiểm định bởi hệ số đường dẫn $(\beta)$ và mức ý nghĩa của chúng bằng mô hình đường dẫn PLS áp dụng quy trình bootstrapping không đối xứng.

\section{Kết quả nghiên cứu}

\subsection{Thông tin chung về mẫu nghiên cứu}

Kết quả phân tích 938 phiếu khảo sát, có 281 bác sỹ (30\%), 447 điều dưỡng (47.7\%), 113 kỹ thuật viên (12\%), 97 dược sỹ (10,3\%); 345 nam (36.8\%), 593 nữ (63.2\%); trình độ đại học 552 (58.8\%), cao đẳng 199 (21.2\%), sau đại học 187 (19.9\%); 614 chưa kết hôn (65.5\%), 324 đã kết hôn (34.5\%); thâm niên công tác từ 5 - 10 năm 278 (30.6\%), dưới 5 năm $246(26.2 \%), 10$ - 15 năm $228(24.3 \%)$, trên 15 năm 177 (18.9\%); độ tuổi 25 - 35 là 432 (46,1\%), 35 - 45 là 318 (33.9\%), trên 45 là $120(12.8 \%)$, dưới 25 là $68(7.2 \%)$.

\subsection{Kiểm định độ tin cậy và tính hợp lệ của thang đo}

Kết quả phân tích cho thấy, hệ số tải nhân tố thỏa yêu cầu. Theo Hair, Sarstedt, Hopkins, và Kuppelwieser (2014) để đánh giá sự nhất quán nội bộ sử dụng độ tin cậy tổng hợp (CR) sẽ tốt hơn. Tất cả 11 biến có $C R$ từ 0.793 đến 0.931 thõa yêu cầu $C R>0.6$. Giá trị hội tụ được kiểm tra bằng phương sai trích trung bình (AVE), AVE phải $>0.5$ (Fornell \& Larcker, 1981), trong bảng 1 cho giá trị $\mathrm{AVE}$ của 11 biến từ 0.533 đến 0.819 thõa mãn yêu cầu.

\section{Bảng 1}

Kết quả phân tích độ tin cậy và tính hợp lệ của thang đo

\begin{tabular}{|l|c|c|c|c|}
\hline & $\begin{array}{c}\text { Số biến } \\
\text { quan sát }\end{array}$ & $\begin{array}{c}\text { Cronbach's } \\
\text { Alpha }\end{array}$ & Hệ số CR & Hệ số AVE \\
\hline Hiệu suất công việc & 6 & 0.824 & 0.872 & 0.533 \\
\hline Kích thích trí tuệ & 4 & 0.732 & 0.830 & 0.550 \\
\hline Phong cách lãnh đạo tự do & 3 & 0.893 & 0.931 & 0.819 \\
\hline Quan tâm cá nhân & 3 & 0.720 & 0.842 & 0.641 \\
\hline Quản lý bằng ngoại lệ chủ động & 3 & 0.617 & 0.795 & 0.567 \\
\hline Quản lý bằng ngoại lệ thụ động & 4 & 0.821 & 0.878 & 0.644 \\
\hline
\end{tabular}




\begin{tabular}{|l|c|c|c|c|}
\hline & $\begin{array}{c}\text { Số biến } \\
\text { quan sát }\end{array}$ & $\begin{array}{c}\text { Cronbach's } \\
\text { Alpha }\end{array}$ & Hệ số CR & Hệ số AVE \\
\hline Sự hài lòng với công việc & 8 & 0.890 & 0.912 & 0.566 \\
\hline Thưởng theo thành tích & 3 & 0.699 & 0.832 & 0.623 \\
\hline Truyền cảm hứng & 7 & 0.875 & 0.903 & 0.573 \\
\hline Ảnh hưởng lý tưởng (hành vi) & 3 & 0.709 & 0.836 & 0.630 \\
\hline Ảnh hưởng lý tưởng (thuộc tính) & 3 & 0.610 & 0.793 & 0.561 \\
\hline
\end{tabular}

Nguồn: Kết quả phân tích dữ liệu của nhóm nghiên cứu

\subsection{Mô hìh cấu trúc}

Sau khi kiểm tra thấy các yếu tố đều đáp ứng được độ tin cậy và tính hợp lệ, mô hình cấu trúc được dùng để kiểm định các giả thuyết nghiên cứu có ý nghĩa thống kê nếu $\mathrm{p}$ - values $\leq 0.05$. Kết quả kiểm định ở bảng 2 cho thấy có 5 giả thuyết được chấp nhận và 14 giả thuyết bị bác bỏ. Đồng thời được tóm tắt bởi Hình 1 .

\section{Bảng 2}

Kết quả của các giả thuyết nghiên cứu

\begin{tabular}{|c|c|c|c|c|c|}
\hline \multirow{2}{*}{$\begin{array}{l}\text { Giả } \\
\text { thuyết }\end{array}$} & \multirow[b]{2}{*}{ Phát biểu } & \multirow{2}{*}{$\begin{array}{c}\text { Kỳ } \\
\text { vọng }\end{array}$} & \multicolumn{3}{|c|}{ Kết quả } \\
\hline & & & $\begin{array}{c}\text { Hệ số } \\
\text { đường dẫn }\end{array}$ & $\begin{array}{c}\text { Giá trị } \\
\text { p }\end{array}$ & $\begin{array}{l}\text { Kết } \\
\text { luận }\end{array}$ \\
\hline H1a & $\begin{array}{l}\text { Ảnh hưởng lý tưởng hành vi của lãnh đạo tác } \\
\text { động đến sự hài lòng }\end{array}$ & + & 0.100 & 0.114 & Bác bỏ \\
\hline $\mathrm{H} 1 \mathrm{~b}$ & $\begin{array}{l}\text { Ảnh hưởng lý tưởng thuộc tính của lãnh đạo tác } \\
\text { động đến sự hài lòng }\end{array}$ & + & 0.130 & 0.014 & $\begin{array}{l}\text { Chấp } \\
\text { nhận }\end{array}$ \\
\hline $\mathrm{H} 1 \mathrm{c}$ & Truyền cảm hứng tác động đến sự hài lòng & + & -0.015 & 0.819 & Bác bỏ \\
\hline H1d & Kích thích trí tuệ tác động đến sự hài lòng & + & 0.051 & 0.355 & Bác bỏ \\
\hline H1e & Quan tâm cá nhân tác động đến sự hài lòng & + & -0.040 & 0.451 & Bác bỏ \\
\hline H1f & Thưởng theo thành tích tác động đến sự hài lòng & + & 0.171 & 0.002 & $\begin{array}{l}\text { Chấp } \\
\text { nhận }\end{array}$ \\
\hline $\mathrm{H} 1 \mathrm{~g}$ & $\begin{array}{l}\text { Quản lý bằng ngoại lệ chủ động tác động đến sự } \\
\text { hài lòng }\end{array}$ & + & 0.117 & 0.016 & $\begin{array}{l}\text { Chấp } \\
\text { nhận }\end{array}$ \\
\hline $\mathrm{H} 1 \mathrm{~h}$ & $\begin{array}{l}\text { Quản lý bằng ngoại lệ thụ động tác động đến sự } \\
\text { hài lòng }\end{array}$ & - & -0.020 & 0.719 & Bác bỏ \\
\hline H1i & $\begin{array}{l}\text { Phong cách lãnh đạo tự do tác động đến sự hài } \\
\text { lòng }\end{array}$ & - & 0.023 & 0.669 & Bác bỏ \\
\hline $\mathrm{H} 2 \mathrm{a}$ & $\begin{array}{l}\text { Ảnh hưởng lý tưởng hành vi của lãnh đạo tác } \\
\text { động đến hiệu suất công việc }\end{array}$ & + & -0.059 & 0.372 & Bác bỏ \\
\hline $\mathrm{H} 2 \mathrm{~b}$ & $\begin{array}{l}\text { Ảnh hưởng lý tưởng thuộc tính của lãnh đạo tác } \\
\text { động đến hiệu suất công việc }\end{array}$ & + & 0.029 & 0.563 & Bác bỏ \\
\hline
\end{tabular}




\begin{tabular}{|c|c|c|c|c|c|}
\hline \multirow{2}{*}{$\begin{array}{l}\text { Giả } \\
\text { thuyết }\end{array}$} & \multirow[b]{2}{*}{ Phát biểu } & \multirow{2}{*}{$\begin{array}{c}\text { Kỳ } \\
\text { vọng }\end{array}$} & \multicolumn{3}{|c|}{ Kết quả } \\
\hline & & & $\begin{array}{c}\text { Hệ số } \\
\text { đường dẫn }\end{array}$ & $\begin{array}{c}\text { Giá trị } \\
\mathbf{p}\end{array}$ & $\begin{array}{l}\text { Kết } \\
\text { luận }\end{array}$ \\
\hline $\mathrm{H} 2 \mathrm{c}$ & $\begin{array}{l}\text { Truyền cảm hứng tác động đến hiệu suất công } \\
\text { việc }\end{array}$ & + & -0.058 & 0.372 & Bác bỏ \\
\hline $\mathrm{H} 2 \mathrm{~d}$ & Kích thích trí tuệ tác động đến hiệu suất công việc & + & 0.069 & 0.223 & Bác bỏ \\
\hline $\mathrm{H} 2 \mathrm{e}$ & $\begin{array}{l}\text { Quan tâm cá nhân tác động đến hiệu suất công } \\
\text { việc }\end{array}$ & + & -0.037 & 0.443 & Bác bỏ \\
\hline $\mathrm{H} 2 \mathrm{f}$ & $\begin{array}{l}\text { Thưởng theo thành tích tác động cùng chiều đến } \\
\text { hiệu suất công việc }\end{array}$ & + & 0.104 & 0.050 & $\begin{array}{l}\text { Chấp } \\
\text { nhận }\end{array}$ \\
\hline $\mathrm{H} 2 \mathrm{~g}$ & $\begin{array}{l}\text { Quản lý bằng ngoại lệ chủ động tác động đến hiệu } \\
\text { suất công việc }\end{array}$ & + & 0.092 & 0.058 & Bác bỏ \\
\hline $\mathrm{H} 2 \mathrm{~h}$ & $\begin{array}{l}\text { Quản lý bằng ngoại lệ thụ động tác động đến hiệu } \\
\text { suất công việc }\end{array}$ & - & 0.019 & 0.726 & Bác bỏ \\
\hline $\mathrm{H} 2 \mathrm{i}$ & $\begin{array}{l}\text { Phong cách lãnh đạo tự do tác động đến hiệu suất } \\
\text { công việc }\end{array}$ & - & -0.013 & 0.807 & Bác bỏ \\
\hline $\mathrm{H} 3$ & Sự hài lòng tác động đến hiệu suất công việc & + & 0.494 & 0.000 & $\begin{array}{l}\text { Chấp } \\
\text { nhận }\end{array}$ \\
\hline
\end{tabular}

Nguồn: Tác giả, 2020

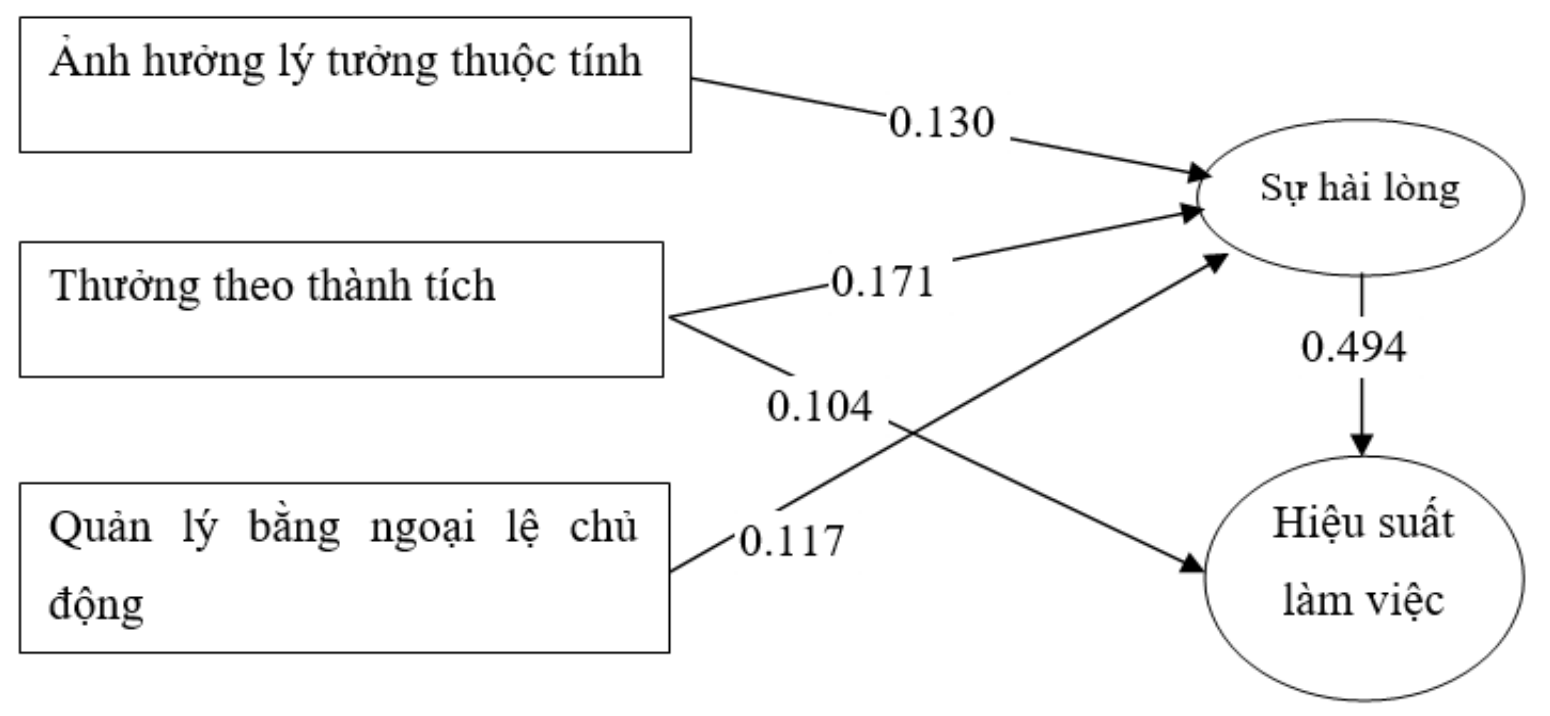

Hình 2. Mô hình đường dẫn

Kết quả nghiên cứu cho thấy chỉ có 1 yếu tố thuộc hành vi lãnh đạo chuyển hóa có ảnh hưởng đến sự hài lòng và không có yếu tố nào có ảnh hưởng ở mức có ý nghĩa thống kê đến hiệu suất làm việc. Điều này khá phù hợp với các nghiên cứu trong nước về mảng này như nghiên cứu của Khang (2013), Thuy (2011), Hoai (2013) nhưng lại rất khác so với nghiên cứu ở các nước ngoài Chaudhry và Husnain (2012), Ahmad, Abbas, và Latif (2017). 
Lãnh đạo trao đổi có tác động mạnh hơn so với chuyển hóa đối với sự hài lòng và hiệu suất làm việc của nhân viên y tế tại các bệnh viện công. Trong đó, thưởng theo thành tích có tác động tích cực đến cả Sự hài lòng $(0.171)$ và Hiệu suất làm việc $(0.104)$ đã được chỉ ra trong nghiên cứu này và ở nhiều nghiên cứu tương tự khác. Do đó, việc thưởng theo thành tích có vai trò quan trọng và cần thiết trong việc tạo sự hài lòng và hiệu suất làm việc cho nhân viên, người lãnh đạo cần quan tâm nhiều hơn đến vấn đề này.

Yếu tố quản lý bằng ngoại lệ chủ động ghi nhận sự tác động cùng chiều có ý nghĩa thống kê đối với Sự hài lòng (0.117). Nó yêu cầu người lãnh đạo chú ý đến những công việc chưa hoàn thành, tập trung giải quyết các sai lầm, những phàn nàn, phân định rõ người chịu trách nhiệm. Đây là những nghiệp vụ cần thiết của người quản lý, giúp cho các sai sót của nhân viên được giải quyết kịp thời và cảm thấy hài lòng vì đã được giúp đỡ.

Yếu tố Ảnh hưởng lý tưởng thuộc tính có tác động tích cực có ý nghĩa thống kê đến Sự hài lòng (0.13). Nó yêu cầu người lãnh đạo phải luôn đặt lợi ích của tập thể lên trên lợi ích cá nhân, người lãnh đạo phải thể hiện quyền lực một cách tự tin, luôn cân nhắc các vấn đề đạo đức trước khi ra quyết định và tạo ra được sự hài lòng cho nhân viên.

Kết quả nghiên cứu chỉ ra có mối quan hệ khá mạnh (0.494), với tác động tích cực của Sự hài lòng công việc đối với Hiệu suất làm việc, phù hợp với nghiên cứu của Pugno và Depedri (2010) cho rằng hiệu suất công việc của nhân viên có thể bị ảnh hưởng mạnh mẽ và tích cực bởi sự hài lòng của họ. Do đó, người lãnh đạo cần quan tâm tạo ra sự hài lòng cho nhân viên. Có rất nhiều giải pháp, nhiều nội dung để tạo nên sự hài lòng cho nhân viên, tuy nhiên việc chọn yếu tố nào cần có sự phân tích, đánh giá thấu đáo trong từng hoàn cảnh cụ thể của từng bệnh viện.

\section{Kết luận và khuyến nghị}

Mục đích của nghiên cứu này là chỉ ra các yếu tố tác động, mức độ và chiều hướng tác động đến Sự hài lòng và Hiệu suất làm việc của nhân viên y tế tại các bệnh viện công lập. Kết quả nghiên cứu cho thấy có 2 yếu tố thuộc hành vi lãnh đạo trao đổi đó là Thưởng theo thành tích và Quản lý ngoại lệ chủ động cùng 1 yếu tố thuộc hành vi lãnh đạo chuyển hóa là Ảnh hưởng lý tưởng thuộc tính tác động có ý nghĩa thống kê và tích cực đến Sự hài lòng và Hiệu suất làm việc của nhân viên y tế tại các bệnh viện công lập. Tuy nhiên, các tác động đều được ghi nhận ở mức thấp. Nghiên cứu cũng cho kết quả sự tác động tích cực với mức độ khá mạnh của Sự hài lòng đối với Hiệu suất làm việc.

Yếu tố Thưởng theo thành tích trong hành vi lãnh đạo trao đổi chỉ ra rằng, người lãnh đạo phải quan tâm rà soát các mục tiêu cần đạt được, khi nhân viên đã làm được các mục tiêu của bệnh viện hoặc khoa, phòng đề ra thì người lãnh đạo cần thể hiện sự hài lòng để ghi nhận, động viên họ. Trong quá trình nhân viên thực hiện các nhiệm vụ, mục tiêu đặt ra thì người lãnh đạo cần phải đáp ứng đầy đủ nguồn lực để họ làm việc. Ví dụ, khi yêu cầu nâng cao chất lượng chẩn đoán và điều trị các ca bệnh khó trong bệnh lý mạch vành thì nhất thiết phải trang bị cho họ hệ thống máy DSA hiện đại ; yêu cầu không để bệnh nhân chờ đợi lâu nhưng vẫn tiếp nhận tất cả bệnh nhân ngoại trú đang quá tải thì phải bảo đảm cho họ có nhân viên, đủ phòng khám với trang thiết bị hiện đại,... Hiện nay Chính phủ ta đã chữa khỏi bệnh cho phi công người Anh bị nhiễm Covid - 19 rất nặng đã sử dụng rất nhiều thiết bị hiện đại như hệ thống ECMO cùng sự hỗ trợ của nhiều chuyên gia trên cả nước, kinh phí điều trị rất lớn và đặc biệt là sự tích cực, nhiệt tình của đội ngũ nhân viên y tế,... Một khi nhân viên của bệnh viện đã có những nỗ lực để đạt được các mục tiêu đề ra nhất là những mục tiêu khó thì cần phải có khen thưởng xứng đáng cho những nỗ lực đó. Việc khen thưởng cũng cần phải được công khai, minh bạch, có tiêu chí rõ ràng, phải bảo đảm đúng người, đúng việc, đúng mức độ. Điều này đòi hỏi các nhà lãnh đạo ở các bệnh viện công cần xây dựng 
các bộ tiêu chí đánh giá nhân viên, đánh giá kết quả thực hiện nhiệm vụ cho từng mục tiêu rõ ràng, định lượng, nếu đánh giá định tính, đại khái, cào bằng nên sẽ không tạo thêm được động lực làm việc thực sự cho nhân viên.

Bên cạnh đó, Yếu tố quản lý bằng ngoại lệ chủ động yêu cầu người lãnh đạo chú ý vào những khuyết điểm của nhân viên, ghi nhớ những lỗi lầm, chú ý đến những công việc chưa hoàn thành, tập trung giải quyết các sai lầm, những phàn nàn, phân định rõ ràng người chịu trách nhiệm về các mục tiêu và đáp ứng yêu cầu của đơn vị hiệu quả. Thực hiện Quản lý bằng ngoại lệ chủ động nó cũng giúp cho người nhân viên cảm thấy tin tưởng hơn người lãnh đạo vì sự cụ thể, tỉ mỉ, đó cũng là điều làm cho người nhân viên gắn bó hơn đối với tổ chức. Tuy nhiên, vấn đề này cũng chỉ nên xem xét quan tâm thực hiện ở người lãnh đạo, quản lý cấp thấp và cấp trung thì sẽ phù hợp hơn.

Nghiên cứu cũng cho thấy hình tượng của người lãnh đạo thông qua Yếu tố Ảnh hưởng lý tưởng thuộc tính nó giúp gia tăng sự hài lòng cho nhân viên và người lãnh đạo cần phải truyền tải và lan rộng tầm ảnh hưởng về hình tượng đó đến các lãnh đạo cấp khác nhau trong bệnh viện, giữa các khoa, phòng sẽ giúp nâng cao hiệu quả của bệnh viện mình. Đặc biệt phải công tư phân minh và minh bạch thông tin với cấp dưới.

Hướng nghiên cứu tiếp theo trong thời gian tới, chúng tôi đề nghị cần xem xét yếu tố Sự hài lòng là biến trung gian giữa hành vi lãnh đạo và Hiệu suất làm việc để đánh giá tổng thể các ảnh hưởng trực tiếp và gián tiếp của các yếu tố thuộc hành vi lãnh đạo trao đổi và chuyển hóa đến Hiệu suất làm việc được đầy đủ hơn. Và nên tách đối tượng bác sỹ riêng để nghiên cứu vì đây là đối tượng có sự khác biệt về yêu cầu đạo tạo, công việc chuyên môn, cơ hội việc làm và là đối tượng có nhiều ảnh hưởng nhất đến việc thực hiện nhiệm vụ của Bệnh viện nên có thể có sự khác biệt trong việc thể hiện sự hài lòng và hiệu suất công việc thông qua tác động của hành vi lãnh đạo.

Nghiên cứu có số lượng giả thuyết bị bác bỏ khá nhiều (12 giả thuyết), điều này cho thấy có sự khác biệt giữa lĩnh vực và môi trường tiến hành nghiên cứu. Đồng thời nó cũng sẽ có những ảnh hưởng nhất định đến kết quả nghiên cứu. Do đó, khi tiến hành nghiên cứu ở các lĩnh vực, các môi trường mới cần tiến hành pilot test.

\section{Tài liệu tham khảo}

Ahmad, F., Abbas, T., \& Latif, S. A. R. (2017). Impact of transformational leadership on employee engagement. Pranjana: The Journal of Management Awareness, 20(2), 15-19. doi:10.5958/0974-0945.2017.00011.5

Ahmad, H., Ahmad, K., \& Shah, I. A. (2010). Relationship between job satisfaction, job performance attitude towards work and organizational commitment. European Journal of Social Sciences, 18(2), 257-267.

Awamleh, R., \& Al-Dmour, H. A.-D. (2011). The impact of transformational leadership on job satisfaction and self-perceived performance of banking employees: The case of Jordan. International Business \& Economics Research Journal (IBER), 3(11), 29-42. doi:10.19030/iber.v3i11.3740

Bass, B. (1985). Leadership and performance beyond expectations. New York, NY: Free Press.

Bass, B., \& Avolio, B. J. (1990). Transformational leadership development: Manual for the multifactor leadership questionnaire. Palo Alto, CA: Consulting Psychologists Press.

Bryman, A. (1992). Charisma and leadership in organizations. London, UK: Sage London. 
Burns, J. M. (1978). Leadership. New York, NY: Harper \& Row.

Chaudhry, A. Q., \& Husnain, J. (2012). Impact of transactional and laissez faire leadership style on motivation. International Journal of Business and Social Science, 3(7), 256-264.

Colquitt, J., Lepine, J. A., Wesson, M. J., \& Gellatly, I. R. (2011). Organizational behavior: Improving performance and commitment in the workplace. New York, NY: McGrawHill/Irwin.

Faraz, N. A., Raza, A., Yanxia, C., Ahmed, F., \& Estifo, Z. G. (2018). The influence of transactional leadership on innovative work behavior-a mediation model. European Journal of Business and Social Sciences, 7(1), 51-62.

Fornell, C., \& Larcker, D. F. (1981). Evaluating structural equation models with unobservable variables and measurement error. Journal of Marketing Research, 18(1), 39-50. doi: $10.2307 / 3151312$

Gruneberg, M. M. (1979). Understanding job satisfaction (1st ed.). London, UK: Palgrave Macmillan.

Hair, J. F., Sarstedt, M., Hopkins, L., \& Kuppelwieser, V. G. (2014). Partial Least Squares Structural Equation Modeling (PLS-SEM): An emerging tool in business research. European Business Review, 26(2), 106-121. doi:10.1108/EBR-10-2013-0128

Hoai, A. T. (2013). Mối quan hệ giũa phong cách lãnh đạo và hành vi nhân viên: Kiểm chúng tại các doanh nghiệp buu chính Việt Nam 2013 [The relationship between leadership styles and employee behavior: A test in Vietnam postal firms 2013] (Doctoral dissertation). Hanoi University of Science \& Technology, Hanoi, Vietnam.

Hoxha, A., \& Heimerer, K. (2019). Transformational and transactional leadership styles on employee transformational and transactional leadership styles on employee performance asst prof Agron Hoxha. International Journal of Humanities and Social Science Invention (IJHSSI), 8(November), 46-58.

Hulin, C. L., \& Judge, T. A. (2003). Job attitudes. In Handbook of psychology (pp. 255-276). Hoboken, NJ: Wiley.

Khang, L. A. (2013). Nghiên cứu phong cách lãnh đạo chuyển đổi: Sự tín nhiệm và gắn kết tổ chức trong bối cảnh Việt Nam [Research leadership transformational styles: Credibility and organizational cohesion in the Vietnamese context]. Tạp Chí Khoa Hoc Truờng Đại Học Mở Thành phố Hồ Chí Minh, 4(32), 50-60.

Lan, T. S., Chang, I. H., Ma, T. C., Zhang, L. P., \& Chuang, K. C. (2019). Influences of transformational leadership, transactional leadership, and patriarchal leadership on job satisfaction of cram school faculty members. Sustainability (Switzerland), 11(12), 1-14. doi:10.3390/su10023465

Maurya, V. N., \& Kaushik, A. P. (2013). On the job training: A step towards job satisfaction-A case study of public sector organization in Indian scenario. International Journal of Mathematical Modeling and Applied Computing, 1(2), 11-17.

Nazim, F. (2016). Principals' transformational and transactional leadership style and job satisfaction of college teachers. Journal of Education and Practice, 7(34), 18-22.

Pugno, M., \& Depedri, S. (2010). Job performance and job satisfaction: An integrated survey. Economia Politica, 27(1), 175-210. 
Rachmawati, R. (2015). Transformational and transactional leadership effect on job satisfaction in Santika Hotel Bandung. Proceeding of International Conference on Trends in Economics, Humanities and Management (ICTEHM'15) March 27-28, 2015 Singapore, 57-62. doi:10.15242/icehm.ed0315080

Sonnentag, S., \& Frese, M. (2005). Performance concepts and performance theory. In Psychological management of individual performance (pp. 1-25). Hoboken, NJ: Wiley.

Spector, P. E. (1997). Job satisfaction: Application, assessment, causes, and consequences. Singapore: Sage publications.

Thuy, T. T. C. (2011). Ảnh hưởng của lãnh đạo tạo sụ thay đổi đến sự thỏa mãn với công việc và lòng trung thành đối với tổ chức của nhân viên [Leadership influence makes changes to employee satisfaction and organizational loyalty] (Master's thesis). Đại học Kinh tế Thành phố Hồ Chí Minh, Ho Chi Minh, Vietnam.

Tri, C. M., \& Ut, C. T. (2017). Tác động của các nhân tố thuộc phong cách lãnh đạo đến kết quả thực hiện công việc của cán bộ công chức các cơ quan chuyên môn tại tỉnh Sóc Trăng [The impact of leadership style factors on the performance of civil servants and professional agencies in Soc Trang province]. Tạp Chí Khoa Học Đại Học Mỏ Thành phố Hồ Chí Minh, 54(3), 37-57. 